\title{
Green chemistry: deliverance or distraction?
}

\author{
Neil Winterton ${ }^{1}$
}

Received: 2 December 2015/ Accepted: 1 February 2016/Published online: 13 February 2016

(C) The Author(s) 2016. This article is published with open access at Springerlink.com

\begin{abstract}
As the green chemistry principles are increasingly used in teaching chemistry at all levels, this perspective provides a critique of their strengths and weaknesses. It asks whether or not the principles have sufficient scientific validity to aid the proper understanding of the subject (as opposed to highlighting concerns about its application). Furthermore, as the principles are increasingly cited in research papers, it also questions whether evidence exists that they have led to improvements in the sustainability and environmental impact of chemical technology that would not otherwise have arisen as a result of conventional economic, feedstock, competitive, market and regulatory pressures had they not been promulgated.
\end{abstract}

\section{Keywords Green chemistry - Sustainability - Education}

The past twenty or so years have seen the rise of the socalled 'green' chemistry, a movement whose adherents want the discipline to adopt a set of twelve principles (Anastas and Warner 1998) in the belief that, through their application, clean chemical technology will result. The original principles (reproduced in Table 1) encapsulate several worthy-if broadly stated-objectives, including the avoidance of waste formation, limitations to resource and energy use and the greater use of renewables. These are to be achieved through the adoption of simple chemical approaches which include the avoidance of solvents, the use of ambient reaction conditions, the adoption of atomefficient chemical reactions and a preference for catalytic

Neil Winterton

n.winterton@liverpool.ac.uk

1 Department of Chemistry, University of Liverpool, Liverpool L69 7ZD, UK rather than stoichiometric transformations as well as by the redesign of chemical products to eliminate toxicological and environmental impact.

All can agree that seeking cleaner chemical technology is a laudable aim. Indeed, many of those engaged in the development of chemical technologies at the time the principles were first enunciated were of the opinion that, in the main, progress in improved material and energy usage and in environmental performance were being delivered. After all, achieving more efficient (and consequently less waste-producing) chemical processing was one of the central purposes of their activities, driven by a range of economic, feedstock, competitive, market and regulatory pressures. Indeed, such practitioners could reasonably claim that waste formation from chemical technology, as a proportion of output, had long been on a reducing trend (see, for example, Winterton 2011a) and that this was expected to continue. The benefits, however, were being offset by increased demand for chemical products arising from global population growth and from increasing prosperity (Krausmann et al. 2009). While the practical and economic realities of carrying out chemistry on the industrial scale meant that waste could not be eliminated altogether, it was also known, more fundamentally, that processes which produce no waste at all are impossible, even in principle, being contrary to the Second Law of Thermodynamics (Jackson et al. 1993). As James Lovelock (1979) concluded, emissions are not all 'the product of moral turpitude'.

Green chemistry principles now feature in many chemistry teaching programmes. They are also frequently used to justify spending on research and, when research is published, to point to its environmental benefits. It is right, therefore, to examine more critically how close to technological reality the principles are and to ask what additional environmental benefits they have brought. 


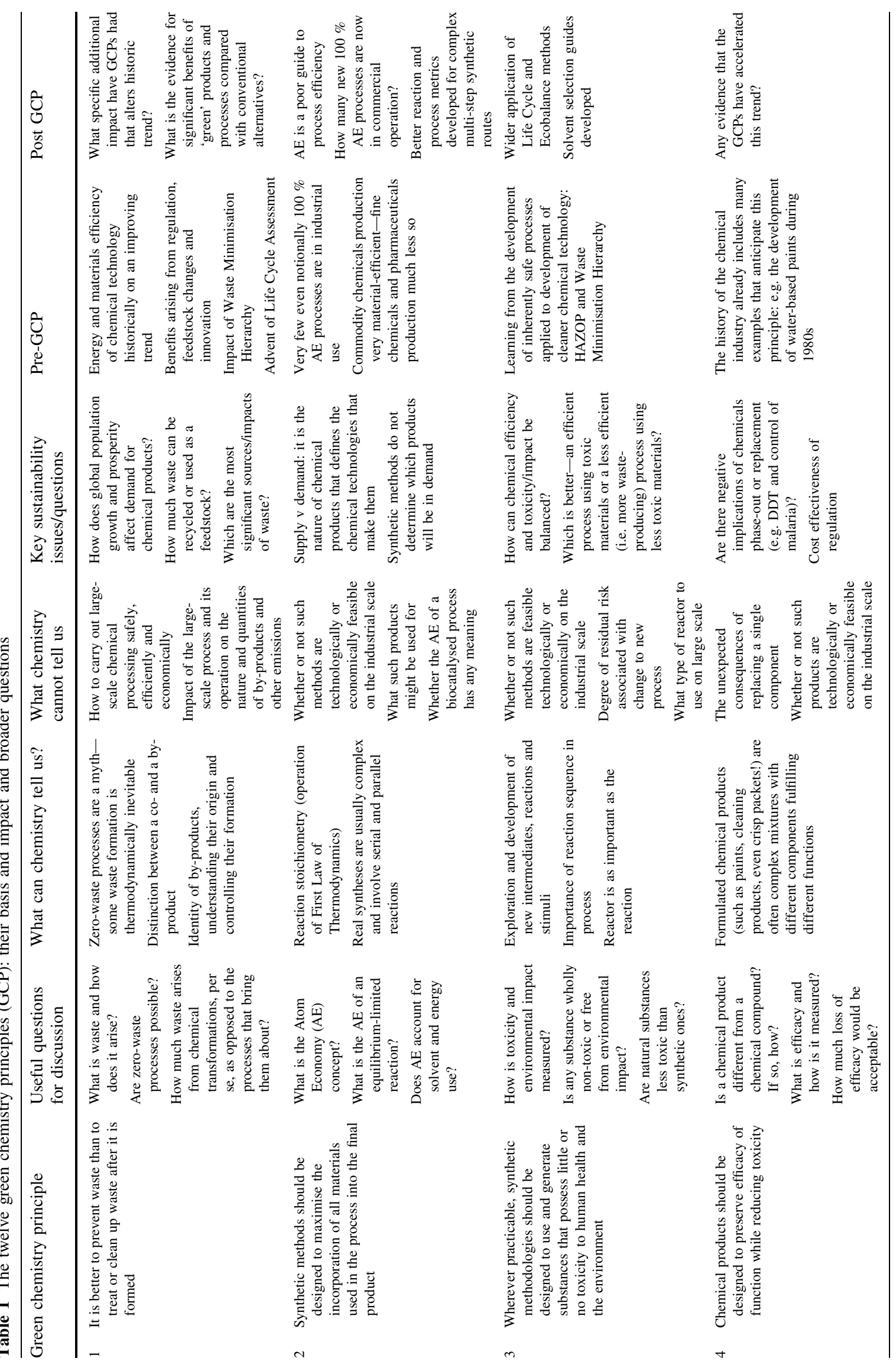




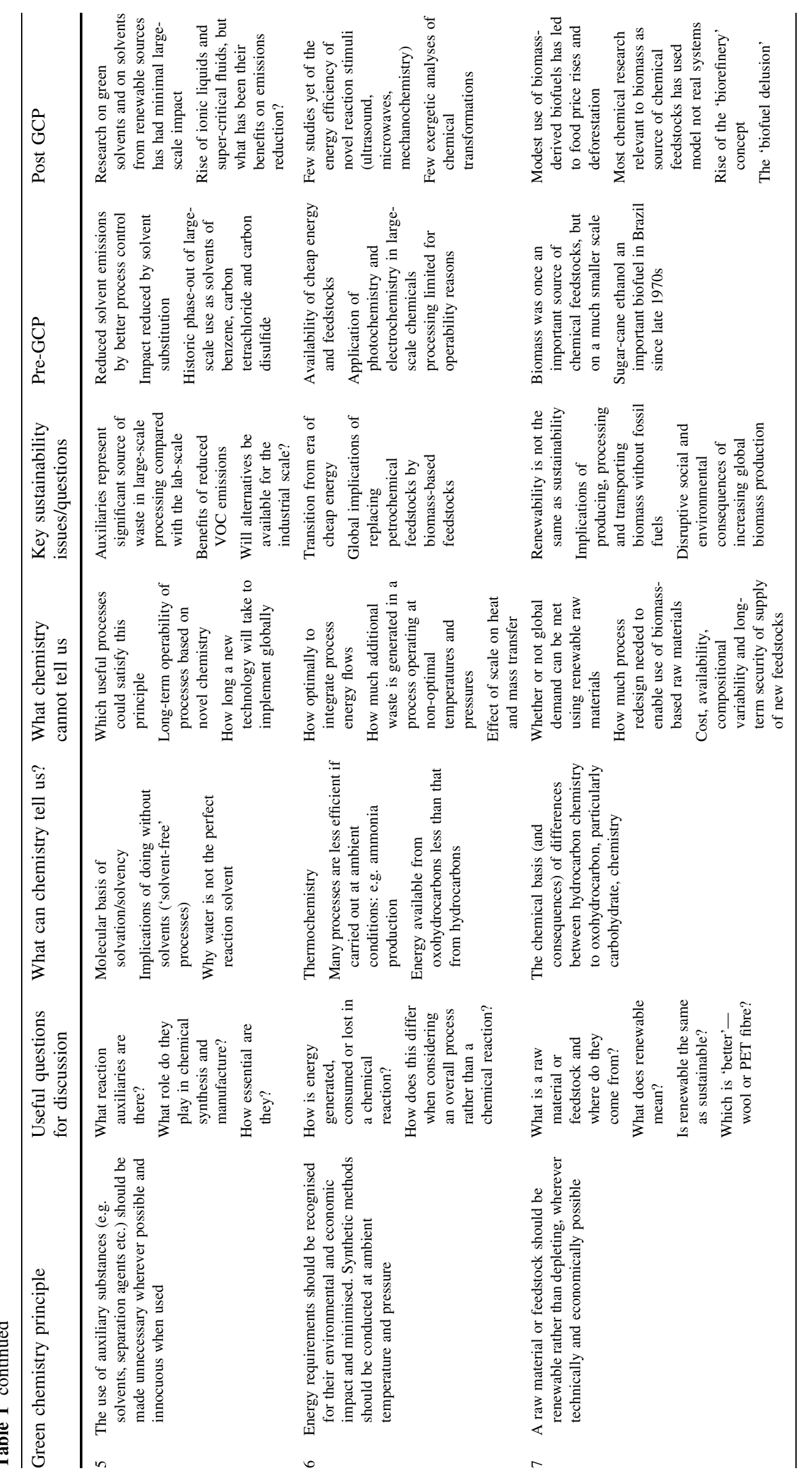




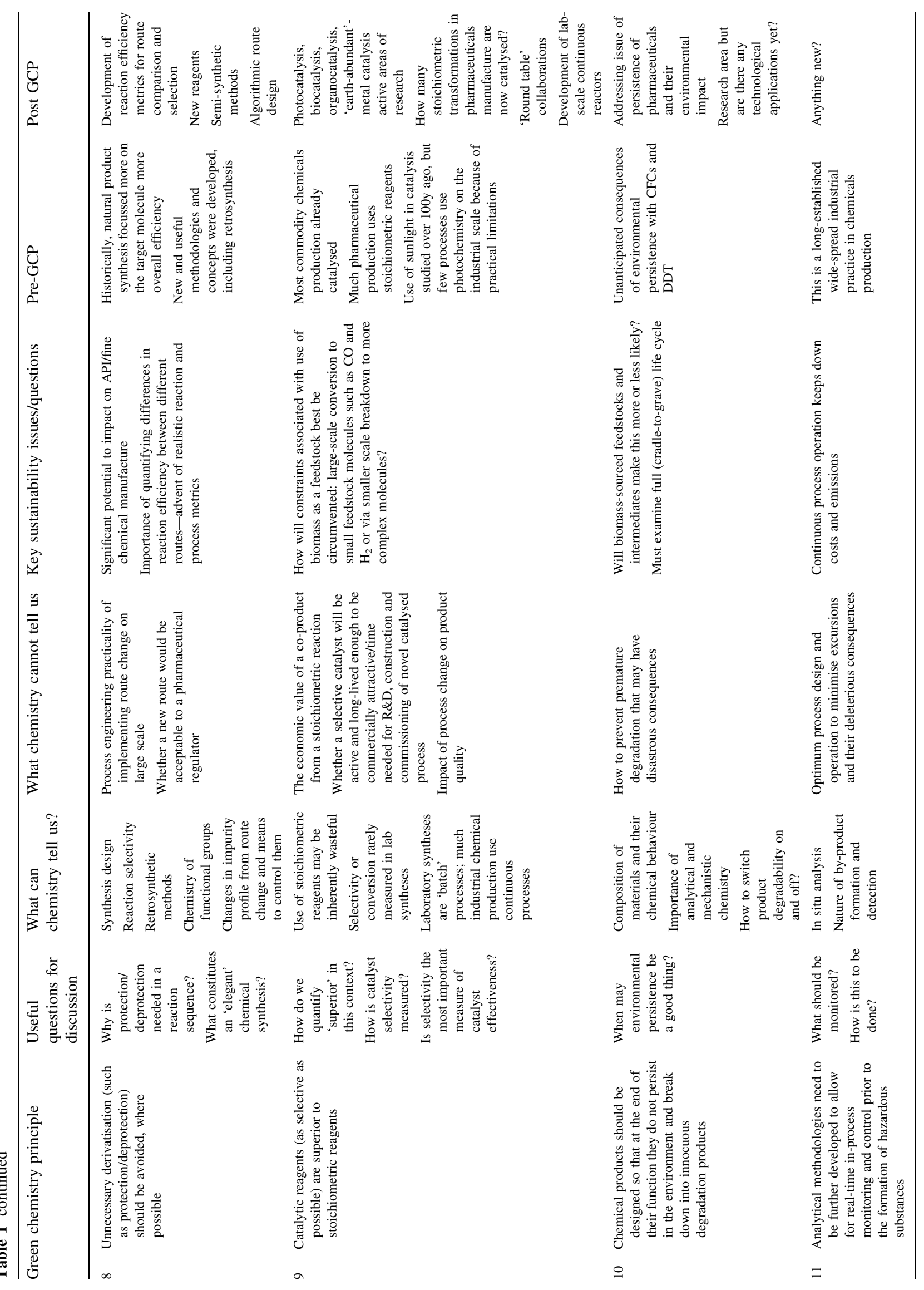




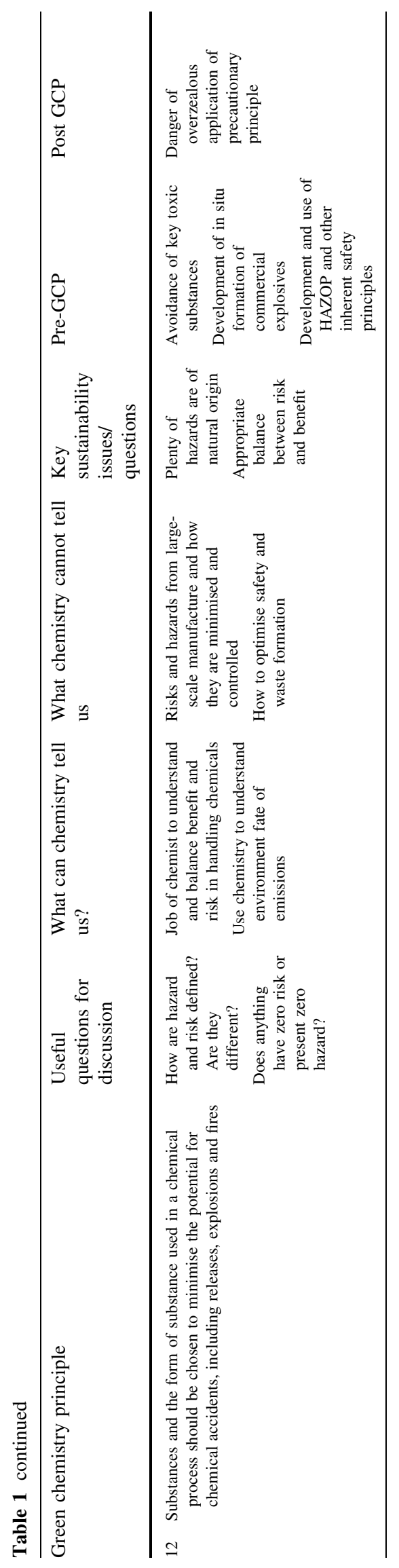

The green chemistry principles provide handy context to highlight self-evident (and historically well-recognised) challenges associated with chemical production and use in a world with a growing global population. On the other hand, these challenges, and the solutions to them, are associated with more than just one sector of industry, let alone a single scientific discipline. Indeed, it can be argued that the green chemistry movement has been overtaken by, and should now be subsumed into, responses to global societal concerns about how to live more sustainably. Teaching about sustainability and sustainable development certainly has a place in education at appropriate stages, but, to be taught effectively, it needs to encompass a range of disciplines and domains much wider than chemistry (or even chemical technology). Chemistry itself should be taught, like other sciences, primarily to develop understanding and stimulate curiosity.

The very effective promotion of green chemistry and the resonance of its message together give rise to a very specific concern. In the teaching of chemistry, there is a risk that the green chemistry principles may appear to be more important than-or, worse, displace-fundamental and often more difficult aspects of the subject, such as the laws of thermodynamics and their everyday significance and practical consequences. These laws underpin any understanding of the discipline of chemistry and, crucially, the possibilities for cleaner chemical technology. They also shine a spotlight on the limitations of the green chemistry principles themselves. It is reasonable, therefore, to ask what standing the principles should have in guiding chemistry as an academic subject, whether taught or researched (as opposed to one to be technologically applied), especially as there are no equivalent principles of green physics or green biology.

First, we should ask whether there is an agreed objective definition of 'green' in the context of chemistry. Except as a description of colour, there is not. 'Green', however, now also has a much wider non-chemical meaning equating to 'in harmony with the environment'. It is hard to identify another area of physical science associated with so vague and subjective a term. A critical operational question arises: do the twelve principles provide a means of establishing the degree to which a chemical transformation, $\mathrm{A}+\mathrm{B} \rightarrow \mathrm{C}+\mathrm{D}$, can, objectively, be considered 'green'? Unfortunately, this simply changes the question. Are there absolute criteria for 'greenness' we should use? If so, what are they? Or should we compare one way of transforming $\mathrm{A}$ and $\mathrm{B}$ into $\mathrm{C}$ and $\mathrm{D}$ with another? If so, what should be the basis of comparison? To start with there is the difficulty of agreeing what a 'waste' might be. Is this limited to that arising from the transformation itself? If $\mathrm{C}$ is the target should co-product, D, be considered a waste? Are waste by-products formed in secondary or side reactions? Do we 
include wastes associated with the procedure that brings the transformation about? What about the identity, quantity and impact of the wastes associated with the supply chains leading to A and B; or those arising from the provision of utilities, such as steam for heating, and auxiliary materials, such as solvents, extractants and gases? Developing and applying robust methods to provide answers to such apparently simple questions is a specialism in its own right, Life Cycle Assessment (Klöpffer and Grahl 2014), one in which chemistry, as a discipline, plays only a modest part.

Furthermore, any such assessment is irrelevant without properly considering the question of 'scalability' (Winterton 2011b), i.e. the feasibility, requirements and consequences of implementing and operating a process for the conversion of A and B at the industrial scale. Any implication that chemistry is able to bring efficiency and environmental benefits to chemical technology on its own is seriously misleading (if not unintentionally hubristic). If green chemistry principles are to be taught in chemistry courses, then a caveat must be entered to the effect that chemistry, while being necessary to bring about technological improvement, is certainly not sufficient (Winterton 2011c). Explicit reference should be made to the essential role that chemical engineering, process economics, feedstock supply, the management of energy, utilities and resources, the function of markets and regulation all play in the development and operation of more efficient large-scale chemical technology. Chemistry and chemical technology are two sides of a single coin (Winterton 2012). Without an appreciation of both, chemists (and others) will acquire an erroneous impression of the contributions realisable by following the path ordained by the green chemistry principles (the 'deliverance').

When publishing research (whether undertaken with a 'green' motivation or not), it might seem obvious to expect that any claim that a new transformation, process, product or solvent provides an environmental benefit would, as urged by Glaze (2000) when editor of the journal Environmental Science and Technology, be based on data sufficient to gauge that which would arise from its large-scale technological application. Unfortunately, an unacceptably large proportion of research papers citing green chemistry principles, if they provide such evidence at all, present data that are limited in scope and relevance and frequently selected to support the proposition of a benefit. Unless a balanced perspective, based on all the evidence, for or against, can be provided, 'green' claims should be avoided. Furthermore, few studies (Zhang et al. 2008) report meaningful comparisons between a new, supposedly 'green', product, process or transformation and an existing equivalent that it is designed to replace. Why do referees and journal editors go along with this? If any other aspect of a research paper were similarly under-supported by the evidence presented, referees would feel it their duty to point out the deficiencies and editors expect them to be addressed before the paper could be considered fit for publication. Searching questions about 'green' claims (Fegade 2015a, b; Fegade and Trembly 2015) should be seen in this light and not assumed to be critical of the idea of environmental improvement, per se, (as they often are perceived to be). Money, resources and effort (and research programmes devoted to green, clean or sustainable chemistry have secured enormous amounts of all three), possibly more beneficially expended elsewhere, can all-too-easily be wasted pursuing 'green' herrings (the 'distraction'). For instance, a depressingly large number of research papers describe 'solvent-free' preparations that turn out to be no such thing. Much wonderful research has appeared on the so-called 'green' solvents and some of it is leading to valuable innovation. However, it can be argued that by far the greater contribution to the reduction in solvent emissions has come not from 'green' solvents (Ashcroft et al. 2014) but from technological trends (solvent substitution, better 'housekeeping, regulation) already well advanced before the advent of green chemistry. The development of water-based paints during the 1980s represents a good example.

Part of the problem lies with the difficulty of developing objective, practical and relevant measures ('green' chemistry metrics (Lapkin and Constable 2008)) of chemical reaction efficiency that may inform operations on the large scale. The realisation of the need for such measures has followed the promotion of green chemistry. It is, of course, impossible to say whether these, or something like them, would or would not have been developed without its stimulus. However, we should challenge any subjective assertion that improvements in the environmental performance of chemical technology since the 1990s that are consistent with one or more of the principles have come about by their conscious application rather than by continued economic, feedstock, competitive and regulatory pressures. The difficult task of developing metrics that are widely applicable and link reaction and process metrics with potential impact has begun, with the contributions of Andraos (2013) being particularly noteworthy.

It seems astonishing that chemists might believe the green chemistry principles to be self-evident statements that are beyond challenge and can be invoked without evidence. This would be dangerous. No scientist should accept a scientific statement simply because someone asserts it. (And if they are not scientific statements what place do they have in the teaching of a scientific discipline?) This is especially true if it concerns a matter where sympathy with a point of view-such as protecting the environment-might be assumed. If the appreciation of the significance of so fundamental a tenet of science, once seen 
as obvious, has diminished, then this needs to be rectified by its formal inclusion in the teaching of science. Examination of the green chemistry principles could provide an excellent opportunity to do this. It is not without significance that the Royal Society, one of the first learned societies - founded in 1660 - took as its motto 'nullius in verba'-'take nothing on authority'. This scepticism is as valid today as it ever was, particularly as the interface between evidence and opinion, even in scientific papers, becomes ever more blurred.

If the green chemistry principles are to be presented to students in academic chemistry courses, then, at the very least, their scientific content and utility should be examined as critically as any other concept. The exhortatory and broad-brush language in which the principles are framed should naturally give rise to questions about the practicality and the circumstances of their implementation. Without answers to these questions, the principles simply remain as worthy aspirations. Surprisingly, few critical assessments (Winterton 2011c) have been published. Only rarely do articles highlight their limited scope and deficiencies or discuss the misunderstandings (Clark 2012) that can result.
However, it is a simple calculation (Winterton 2011d) to establish that replacing the output of just one of the more than 70 world-scale plants capable of producing 500000 tonne year ${ }^{-1}$ of poly(ethylene terephthalate) would require an area the size of Holland just for pasture for sheep. A little-appreciated benefit of chemical technology is how relatively little land is needed to produce a synthetic material (such as a man-made fibre) in enormous quantities compared with production of a biomass-based equivalent. Such 'back-of-the-envelope' calculations should be routinely done (and the capability to do them taught early). It is also difficult to see how the 1 cubic mile of oil (Crane et al. 2010) we use every year can readily be replaced by harvesting biomass, solar or wind power (or even nuclear). The idea that sufficient biomass can be grown to replace all transportation fuels has been called, in a serious and wellargued analysis (Giampietro and Mayumi 2009), the 'biofuel delusion'.

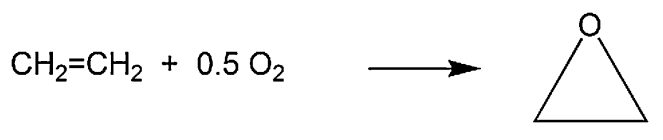

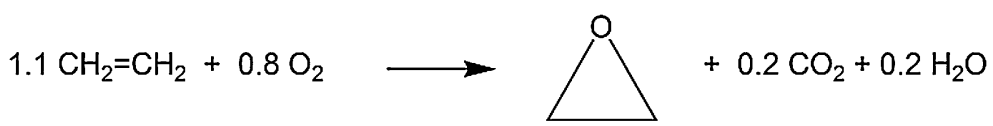

Some of these questions are addressed in the table. A selection is dealt with in more detail below.

The questions on which the table is based are designed to prompt consideration of the nature of, and limits to, the contribution of chemistry to the principles' objectives and of broader questions of sustainability, particularly the context in which global chemical technology will operate in the future. As reductions in environmental impact are a feature of the history of chemical technology, it is quite difficult to distinguish between developments that continue this trend and other outcomes that have arisen specifically from the application of the green chemistry principles, per se, and which might not have occurred without their formulation.

The chief criticism to be levelled against the principles is their failure to consider whether any discovery or innovation based on them can be scaled to the industrial level. The replacement of a man-made fibre, such as poly(ethylene terephthalate), manufactured conventionally from petrochemical feedstocks with a natural and renewable equivalent, such as wool, might be considered a good example of the application of principle 7. What could be better than producing a very useful fibre (wool) directly?
There are very few chemical transformations at the heart of commodity chemical processing based on petrochemicals that approach perfect atom efficiency, the concept that is the basis for principle 2. Even so, such technology produces relatively little waste, being highly integrated, with by-products from one process used as feedstocks for the others. One process, in operation for over 50 years, converts ethylene and oxygen to ethylene oxide in a catalysed transformation (Eq. 1) that would seem to have an atom efficiency of $100 \%$. In reality, however, a fraction of ethylene is found to react with oxygen by a different path to produce waste by-products, carbon dioxide and water (Eq. 2) that reduces $\mathrm{AE}$ to $78 \%$, a matter of some technological importance. Clearly, the selection and formulation of the catalyst and the design and operation of the process seek to limit this 'burning', but to date commercial production of ethylene oxide cannot avoid it completely. Such by-product formation is a significant factor in almost all chemical processing but the original green chemistry principles ignore this aspect altogether. (However, see principle 1 in (Winterton 2001)). Atom efficiency does not address formation of by-products, the need for their separation nor the associated energy use. Nor does AE address 
questions that arise from reactions that are equilibrium limited which require stoichiometric excesses to achieve practical levels of conversion.

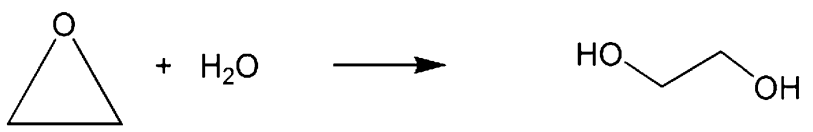

notionally $100 \% \mathrm{AE}$; the second-reaction of ethylene carbonate with water (Eq. 6) -with a notional AE of $62 \%$ ), oligomer formation is reduced by a factor of 100 , water usage is reduced by $30 \%$ and of steam by $20 \%$ (Lange 2009). No wonder this process has been operated commercially. This example illustrates a second important weakness of the green chemistry principles: while they highlight the material aspects of chemical transformations,

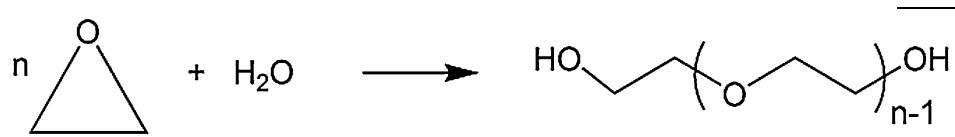

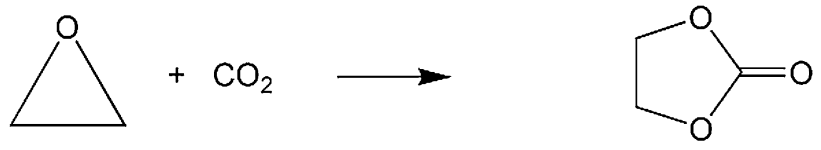

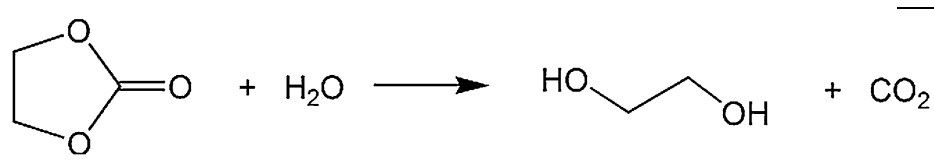

there is only limited focus on energy and utilities usage. One perhaps can see why. Laboratory chemists tend to take for granted the costs and consequences of providing and using utilities, such as electricity and water, in chemical synthesis. They do not, directly, have to pay for them. Even the one principle (principle 6) that addresses energy usage suggests, naively, that processes should be carried out at
As atom efficiency is widely used in green chemistry teaching, the most basic point to be explained to those learning the subject is that industrial processes do not follow idealised stoichiometries, nor are they laboratory transformations done on a large scale. There are technological, economic and regulatory constraints, barely addressed in the twelve principles, which need to be overcome to turn a chemical reaction into an operable and viable process. Three examples illustrate different aspects of this point. First, perhaps surprisingly, $100 \%$ AE processes are not necessarily 'green', if by green we mean more efficient in the use of energy and materials. A chemist might suggest making ethylene glycol from the reaction of ethylene oxide and water (Eq. 3), another notionally $100 \%$ $\mathrm{AE}$ transformation. However, someone wanting to make ethylene glycol on the 100,000 tonne/y scale would soon discover that not all the ethylene oxide ends up as ethylene glycol. Instead, ca $10 \%$ reacts with itself to give oligomeric material (Eq. 4), a by-product that must be separated from the desired product by distillation, an energy-consuming (and costly) operation. By dividing the process into two separate steps (the first-formation of ethylene carbonate from ethylene oxide and carbon dioxide (Eq. 5) - ambient pressure and temperature. Those that can, of course, will be so operated; and, in the past, will have been, because it would be a waste of money to use high temperatures and pressures unnecessarily.

Ammonia production represents a second example to illustrate my criticism. The Haber process, developed 100 years ago, produces ammonia from the catalysed reaction of dinitrogen and dihydrogen (satisfying both principle 9 and (with a notional AE of $100 \%$ ) principle 2). Unfortunately, Le Chatelier's principle (as every chemistry student knows) states that this exothermic reaction is favoured by low temperatures and, because $4 \mathrm{~mol}$ of reactant form 2 mol of product, high pressures. Unfortunately, the reaction is too slow at low temperatures and the costs of plant able to operate at very high pressures are too great. A compromise set of conditions allows equilibrium conversions that are less than $100 \%$ to be achieved reasonably quickly. However, they require the separation and recycle of unconverted reactants, both waste-producing operations in themselves. The Haber process, which satisfies the global demand for anhydrous ammonia, is sometimes compared unfavourably with biological fixation of nitrogen, which does, indeed, occur at ambient 
temperatures and pressures and in water. The reason why industrial technology cannot do the same relates again to questions about the energy requirements of the reaction (of which chemistry students need to be made aware). Nitrogenases 'fix' nitrogen by a chemical reduction involving nicotine adenine dinucleotide (NADH) shown in Eq. 7 (the $\mathrm{AE}$ of which $(<0.5 \%)$ has little meaning), but this is reliant upon the energy provided by a co-reaction in which $16 \mathrm{~mol}$ of adenosine triphosphate (ATP) per mole of nitrogen is hydrolysed to $16 \mathrm{~mol}$ of adenosine diphosphate (ADP). Biological processes have evolved to capture and utilise an endless supply of solar energy to drive the production of ATP from ADP, something technology cannot yet do and biologists do not fully understand (Lane 2015). treatment to remove moisture. Significantly, biomass is edible and we share it with an entire ecological system of which we are part and on which we depend for survival.

Society as a whole has come so completely to rely on cheap and readily available sources of energy and materials through access to fossil resources such as oil, coal and natural gas that the extent of the challenge facing humanity in seeking to move to more sustainable ways of supporting ourselves has not been sufficiently recognised by the public. One credible estimate (Dukes 2003) suggests that each 50-L tank of petrol/gasoline we use has arisen for more than 1000 tons of prehistoric biomass. I estimate ${ }^{1}$ that providing straw as the source of energy (without even addressing what fuel and propulsion system would be

$$
\begin{gathered}
\mathrm{N}_{2}+4 \mathrm{H}_{2} \mathrm{O}+4 \mathrm{NADH}+\left(16[\mathrm{ATP}]^{4-}+16 \mathrm{H}_{2} \mathrm{O}\right) \\
\downarrow
\end{gathered}
$$

$2 \mathrm{NH}_{3}+\mathrm{H}_{2}+4 \mathrm{OH}^{-}+4 \mathrm{NAD}^{+}+\left(16[\mathrm{ADP}]^{3-}+16\left[\mathrm{PO}_{4}\right]^{3-}+32 \mathrm{H}^{+}\right)$

Thirdly, green chemists talk optimistically of using biomass (in a 'biorefinery') to substitute feedstocks, intermediates and products currently derived (in an oil refinery) from geological stores of oil, coal and natural gas. However, chemistry cannot answer the profound social, economic and technological questions that must arise when considering the implications of the differences between modern biomass and the present form of ancient biomass (Winterton, invited lecture, 2nd International Congress on Sustainability Science and Engineering, Tucson, AZ, 11 January 2011). Oil exist as historic stocks, formed over millions of years, with ancient biomass having been given a geochemical 'upgrade' to increase its energy content. It is easy to transport, ready to use with the minimum of pretreatment. Its handling and processing are not labour intensive. Furthermore, its sources are, relatively speaking, localised. It is inedible and, as a consequence, is for our sole use. Contrast this with modern biomass. This is characterised more as being available one year's production at a time from highly distributed locations in a wide range of forms, all vulnerable to adverse weather, disease and infestation. Compared with oil and gas, biomass is difficult to store, transport and process. Without the use of fossil resources, its production is highly labour intensive. Being largely composed of carbohydrates and other oxygenated organics, it has, compared with petrochemicals, significantly lower energy content, ton for ton. As a result, more of it must be used to deliver energy equivalent to that from fossil-sourced materials; or a significant fraction must be used to 'upgrade' the rest. Biomass also requires pre- needed) to power jet air travel in the USA for a year would require an area of farmland equivalent to the size of Spain. Were we to seek to avoid using modern agricultural methods, including synthetic fertilisers and mechanised planting and harvesting equipment, yet more land would be needed to provide output to replace lower yields, as well as additional labour to plant, tend and harvest it. If we were to retain modern methods without access to fossil fuel, we would need to grow additional biomass to replace the latter to power the agricultural system.

There is no doubt humanity is faced with multiple challenges, political, social and environmental, with a variety of prescriptions proposed to address them sustainably. These include arguments for and against the role of technology, including chemical technology, seen simultaneously as the cause of, and solution to, these challenges. It is perhaps understandable that believers in the green chemistry movement overlook the deficiencies of the principles because of the transparent worthiness of their aims. More cynically, those seeking research funding and evidence of impact will hardly highlight the weaknesses of the principles they invoke as motivation of their work,

\footnotetext{
$147 \times 10^{6} \mathrm{t}$ aviation jet fuel consumed annually in the USA. Energy content of jet fuel and straw (20\% moisture) is 43 and $15 \mathrm{MJ} \mathrm{kg}^{-1}$, respectively. Straw with equivalent energy content: $127 \times 10^{6} \mathrm{t}$. Straw productivity ca $2.5 \mathrm{t} \mathrm{ha}^{-1}$. Land area needed: $50.8 \times 10^{4} \mathrm{~km}^{2}$. Land area of Spain: $50.5 \times 10^{4} \mathrm{~km}^{2}$.
} 
particularly as it can be presented as having potentially beneficial consequences. But then, of course, much chemistry research that does not invoke these principles may equally result in similar benefits. We cannot know. Bearing in mind that consumers and activists can, using social media, make or break corporate reputations, it is also unsurprising that companies that sell products whose effectiveness and availability is reliant upon the chemist's art will seek to shift responsibility to chemical manufacturers should questions of environmental impact arise. Furthermore, the benefits to corporate reputations that may arise from the receipt of a green chemistry award may also dampen any unease at claiming that the development of a new product or process is driven by green chemistry principles rather than admit to the more prosaic motivations of market development, competition, cost reduction or straightforward innovation that may well have led to the development anyway. Much, therefore, depends on perception and personal attitudes. However, one would hope that rational thinking using well-founded evidence would be basis of any debate or decision-making in moving towards better and more effective sustainable technologies.

This raises the question of whether chemistry should be held uniquely responsible for waste production to the extent that those who are fascinated by the nature of chemical phenomena and wish to understand their underlying origins must be guided in their future behaviour. Are those who learn, teach and explore any other scientific discipline subject to similar strictures? Surely, physics, biology, geology and mathematics all have applications which may have (or have had) deleterious as well as beneficial consequences. All are a manifestation of the impact of knowledge and how members of society choose to use and exploit it, for good or ill. It is a knotty issue to decide to what extent that those who reveal knowledge are thereafter responsible for the ills of its application. This has given rise to much soul-searching and ethical argument, leading to passionate involvement in the public and political arena. However, this has always, until now, been kept out of the teaching of the subject itself, particularly at its early stages. In addition, concern for the environment and recognition of the importance of minimising the impact of chemical technology are attitudes that pre-date the advent of green chemistry. The wider sustainability movement can be seen as overtaking green chemistry, particularly as it addresses more complex societal questions that I criticise green chemistry for not explicitly addressing. Urging both those who develop and operate chemical technologies and those who use and benefit from their products, to be more mindful of the impact that they may have is clearly no bad thing. But these exhortations, in addition to seeking to direct research effort, also seek to influence behaviour. Indeed, a definition of a principle found in the Oxford
Shorter English Dictionary is 'a general truth as a guide to action'. But what truth? That chemistry as a scientific subject bears the primary responsibility for pollution and the emission of waste and chemists must mend their ways and follow the green path? This over-simplistic analysis focusses too narrowly, as waste, its origins and impact, is a complex societal problem linked to the attitudes and behaviour of a rapidly growing global population of such significance that its beginnings in the eighteenth century are now considered to mark a new geological epoch known as the Anthropocene. Addressing humanity's response to such epochal change requires a transition to more sustainable ways of living, one that involves many fundamental changes in which chemists have a part to play, both as specialists and as citizens. It is to chemists that this article is primarily addressed and I urge the following:

To teachers and educators:

Teach from an early age the practical and everyday relevance of thermodynamics as this will enable students properly to appreciate the strengths and weaknesses of the green chemistry principles;

Place chemistry in the proper context, whether technologically, societally or environmentally;

Teach the central tenets of science relating to evidence, open-minded scepticism, objectivity and self-criticism.

To researchers and authors:

Do not make unsupported or selective 'green' claims; Highlight and seek to understand (if not address) the constraints that hinder large-scale application of discoveries and innovation; see such constraints as opportunities for research.

To referees and editors:

Challenge vague or one-sided claims of environmental benefit; for instance, test whether 'solvent-free' processes are really so;

Require the reporting of evidence to substantiate claims of environmental benefit;

Test whether such claims address large-scale applicability.

In our teaching of chemistry, and our articulation of its role in modern society, do we get the balance right between the excitement of the new and the profundity and importance of the old? Are our students, at school, as undergraduates and in the research laboratory, equipped with a proper understanding of the ethos and values of science and its foundation so they can continue the task of addressing the most difficult intellectual challenges in science and the greatest societal problems human-kind currently face? Is not getting this right the most important legacy that one generation can hand on to the next? As others have said, to bring about a more sustainable way of 
living, human-kind-collectively and individuallyneeds to combine a 'deeper kind of prudence' (Freudenburg 1988) with a 'capacity to worry intelligently' (Kates 1977).

Open Access This article is distributed under the terms of the Creative Commons Attribution 4.0 International License (http://crea tivecommons.org/licenses/by/4.0/), which permits unrestricted use, distribution, and reproduction in any medium, provided you give appropriate credit to the original author(s) and the source, provide a link to the Creative Commons license, and indicate if changes were made.

\section{References}

Anastas PT, Warner JC (1998) Green chemistry: theory and practice. Oxford University Press, Oxford

Andraos J (2013) Safety/Hazard Indices: completion of a Unified Suite of Metrics for the Assessment of "Greenness" for Chemical Reactions and Synthesis Plans. Org Process Res Dev 17:175-192

Ashcroft CP, Dunn PJ, Hayler JD, Wells AS (2014) Survey of solvent usage in papers published in organic process research and development 1997-2012. Org Process Res Dev. doi:10.1021/ op500276u

Clark J (2012) The 12 misunderstandings of green chemistry. Env Sci Eng Mag May 2012, p 6

Crane HD, Kinderman EM, Malhotra R (2010) A cubic mile of oil: realities and options for averting the looming global energy crisis. Oxford University Press, Oxford

Dukes JS (2003) Burning buried sunshine: human consumption of ancient solar energy. Clim Change 61:31-44

Fegade SL (2015a) What is so green about multi-walled carbon nanotubes based composite membranes? Sep Purif Technol 151:95-96

Fegade SL (2015b) Questionable green ionic liquid: comment on "Extractive Desulfurization of Liquid Fuels by Energy Efficient Green Thiazolium based Ionic Liquids". Ind Eng Chem Res 54:2259

Fegade SL, Trembly JP (2015) Dispute over designating an ionic liquid as a green solvent. Chem Eng J 273:668
Freudenburg WR (1988) Perceived risk, real risk: social science and the art of probabilistic risk assessment. Science 242:44-49

Giampietro M, Mayumi K (2009) The biofuel delusion: The fallacy of large scale agro-biofuel production. Earthscan, London

Glaze WH (2000) Editorial. Environ Sci Technol 34:449A

Jackson T, Constanza R, Overcash M, Rees W (1993) The biophysical economy: aspects of the interaction between economy and environment. In: Jackson $\mathrm{T}$ (ed) Clean production strategies: developing preventive environmental management in the industrial economy. Lewis Publishers, London, p 17

Kates RW (1977) Assessing the assessors: the art and ideology of risk assessment. Ambio 6:247-252

Klöpffer W, Grahl B (2014) Life cycle assessment (LCA): a guide to best practice. Wiley VCH, Weinheim

Krausmann F, Gingrich S, Eisenmenger N, Erb K-H, Haberl H, Fischer-Kowalski M (2009) Growth in global materials use, GDP and population during the 20th century. Ecol Econ 68:2696-2705

Lane N (2015) The vital question: Why is life the way it is?. Profile Books, London

Lange J-P (2009) Sustainable chemical manufacturing: a matter of resources, wastes, hazards, and costs. ChemSusChem 2:587-592

Lapkin A, Constable D (eds) (2008) Green chemistry metrics. John Wiley \& Sons Ltd, Chichester

Lovelock J (1979) Gaia: a new look at life on earth. Oxford University Press, Oxford

Winterton N (2001) Twelve More Green Chemistry Principles. Green Chem 3:G73-G75

Winterton N (2011a) Chemistry: necessary but not sufficient. In: Winterton $\mathrm{N}$ (ed.) Chemistry for sustainable technologies. A foundation, Royal Society of Chemistry, Cambridge, UK, p 128

Winterton N (2011b) Scalability and scientific due diligence. Clean Technol Environ Policy 13:643-646

Winterton N (2011c) Chemistry: necessary but not sufficient. In: Winterton $\mathrm{N}$ (ed.) Chemistry for sustainable technologies. A foundation, Royal Society of Chemistry, Cambridge, UK, pp 194-252

Winterton N (2011d) Chemistry for sustainable technologies: a foundation. Royal Society of Chemistry, Cambridge, pp 18-21

Winterton N (2012) Chemists and chemical engineers: divided by a common discipline? Curr Opin Chem Eng 1:225-230

Zhang Y, Bakshi BR, Demessie ES (2008) Life Cycle Assessment of an ionic liquid versus molecular solvents and their applications. Environ Sci Technol 42:1724-1730 